\title{
EEN EN ANDER OOR DIE ONTWIKKELING VAN DIE NUWE TESTAMENTIESE WETENSKAP DIE AFGELOPE VYFTIG JAAR
}

\author{
deur \\ Prof. S. P. J. J. van Rensburg
}

\section{Inleiding}

'n Mol wat grawe aan die voet van die Drakensberge kan nie weet van die hoogtes en die uitgebreidheid van hierdie magtige bergreeks nie. Net so onmoontlik lyk dit vir 'n enkele persoon om 'n duidelike oorsig te hê van so 'n geweldige aktiwiteit as wat die Nuwe Testamentiese wetenskap van die 20ste eeu verteenwoordig. Dit kom neer op 'n geweldige worsteling van duisende geleerdes om die boodskap van die Nuwe Testament te verstaan, te deurgrond en te vertolk vir 'n mensheid wat geskok en verbyster is, - en dit binne die bestek van 'n halwe eeu - deur die twee grootste wêreldoorloë wat die wêreldgeskiedenis ken. Dit kom neer op die verantwoordelikheid en die werksaamheid van die teoloë van die Christelike kerk, met die uiteindelike doel om die kerk weerbaar te maak deur die swaard van die Gees, dit is die Woord van God, weerbaar teen die aanslae van die geestelike magte van die duisternis wat in ons eeu so energiek en listig aan die werk is. Om die intensiteit en die uitgebreidheid en die variasie van die Nieu-Testamentiese wetenskap te oorsien en te tipeer, en om die wesenlike in hierdie werksaamheid te tref, is nie 'n eenvoudige saak nie. Wat ons hier probeer doen is om agtereenvolgens opmerkinge te maak oor die werk van die NieuTestamentiese wetenskap, binne sy verskillende vakgebiede in die afgelope halwe eeu. Maar ook so sal die keuse van wat aangeraak word, subjektief, willekeurig, fragmentaries en vlugtig wees.

Miskien sal dit goed wees om met enkele sinne die saaklike verband aan te toon waarin die Nieu-Testamentiese vakke onderling tot mekaar staan. In die sentrum staan die Eksegese. Die werksaamheid wat met behulp van alle beskikbare middels probeer om die Nuwe Testament te verklaar, uit te lê. Hierdie hulpmiddels vir die eksegese word aangedra deur die kanongeskiedenis, die teksgeskiedenis en tekskritiek wat saamgevat word as Algemene Inleiding. Hierby kom die Besondere Inleiding en die Agtergrond van die Nuwe Testament. Die kanon- 
geskiedenis baken vir ons die arbeidsveld ekstensief af, die teksgeskiedenis en tekskritiek doen dit intensief, deur met behulp van die teksgetuies, - en daar is baie, - so na as moontlik aan die oorspronklike teks te kom. Die Besondere Inleiding vra na die historiese ontstaan van die afsonderlike geskrifte van die Nuwe Testament, bv. na die outeur, tyd en plek van ontstaan, doel ens. van elke geskrif. Die Agtergrond van die Nuwe Testament, wat as "Neutestamentliche Zietgeschichte" in Duitsland opgekom het, vra na die toneel, die agtergrond waarop die Christendom en die Nuwe Testament verskyn het. Vir die regte verstaan van die Nuwe Testament is dit nodig om te weet wat die profaan-historiese, godsdienstige, kultuur-historiese, taalkundige e.a. verhoudinge in die eerste eeu was. Al hierdie vakwetenskappe moet die eksegese dien. By hierdie toerusting moet nog dit kom dat die eksegetiese arbeid sig moet bedien van ' $n$ besonne hermeneutiek. Dit is die teorie van die vertolking, die wetenskap van die verstaan, die geheel van die reëls en beginsels waarvolgens die eksegese te werk moet gaan. Maar dan dien die eksegese weer met sy resultate die vakgebiede Nuwe Testamentiese Teologie, Dogmatiek en Christelike Etiek en die vakke van die Praktiese Teologie. Die Eksegese neem 'n sentrale plek in, want hier gaan dit om die verstaan, die sin en bedoeling van die Woord van God.

\section{Die taalkundige Verhoudinge van die Nuwe Testament}

Die besondere taalkundige karakter van die Nuwe Testament het reeds vroeg die aandag getrek. Die Grieks van die Nuwe Testament verskil nie alleen van die klassieke Grieks nie, maar ook van die Grieks van hellenistiese skrywers van die eerste eeu. Hierdie verskil is op verskillende maniere verklaar. Reeds in die 17 de eeu het daar 'n stryd ontbrand tussen die sogenaamde Puriste en Hebraîste. Die Puriste het in die Nuwe Testament suiwer Grieks gevind, en het ywerig gesoek na parallelle uit die attiese skrywers, om die eienaardigheid van die Nieu-testamentiese taal tot ' $n$ minimum te reduseer. Die Hebraîste wou die afwykinge van die klassieke Grieke toeskryf aan die invloed van Hebreeus en Aramees. Maar in die 19de eeu het daar deur die opgrawinge duisende ostraca en papyri uit die Egiptiese woestynsand tevoorskyn gekom, ongekunstelde dokumente uit die daaglikse lewe van die hellenistiese tyd, uitnodigings, kontrakte, kwitansies, besigheidsbriewe, ens. Aan die begin van ons eeu was dit die besondere verdienste van A. Deissmann e.a. 
om hierdie dokumente te ondersoek. $\mathrm{Na}$ berekening was daar ongeveer 550 spesifiek Nieu-Testamentiese woorde, dus eie aan die Nuwe Testament allëén. Deur Deissmann e.a. is in die ostraca en papyi ongeveer 500 van hierdie spesifiek NieuTestamentiese woorde teruggevind, as behorende tot die gewone spreektaal van die eerste eeu, sodat minder as 50 spesifiek Nieu-Testamentiese woorde oorgebly het. Adolf Deissmann het o.a. in sy „Licht vom Osten", 1908 e.a. werke aangetoon dat die taal van die Nuwe Testament nie ' $n$ afsonderlike taal is, omdat dit die heilige taal van die Bybel is nie, maar dat die Nuwe Testament geskryf is in die gewone spreektaal van daardie dae, die omgangstaal van die massas in die Grieks-Romeinse wêreld, die koinẽ dialektos. So het die skrywers van die Nuwe Testament sig in die volkstaal gerig tot die massas, en nie in die eerste plaas tot die literêr-gevormde lae nie. Hierdie ontdekking van Deissmann was van so 'n ingrypende betekenis dat die gevolgtrekkinge daarvan nie meteens oorsien kon word nie! Onder andere moes die betekenis van baie Nieu-Testamentiese woorde en begrippe in die lig van die nuwe gegewens hersien word.

'n Tweede belangrike faktor wat dic taal en styl van die Nuwe Testament beinvloed het, was die feit dat Aramees die spreektaal van Jesus en sy dissipels was. En Aramees was nie maar net 'n lokale dialek van Hebreeus nie, maar éẻn van die groot tale van die Ooste wat in die eeue voor Christus gespreek is van die Eurfraat tot die Nyl. Iets van die Aramese invloed is te merk in die spreekwyse, woordorde, parataksis, proleptiese pronomina, ens. van die Nieu-Testamentiese Grieks. Die betekenis van hierdie Aramese agtergrond is ingesien. Iemand soos Gustav Dalman het ' $n$ groot deel van sy lewe in Palestina deurgebring om die Aramese oorspronge van die Sinoptiese tradisie na te vors. In „Die Worte Jesu” 1930, e.a. werke het hy die woorde van Jesus gesien teen die agtergrond van die na-kononieke Joodse geskrifte en van die Aramese taal. $\mathrm{Hy}$ het baie gedoen om die belangstelling van die student te wek vir die Aramese oorspronge van die Evangelies. Hy het dit as baie waarskynlik beskou dat ons Sinoptiese Evangelies vertalings van oorspronklik Aramese geskrifte was. Hy kon dit egter nie bewys nie. Reeds in 1922 het C. F. Burney probeer bewys dat die Johannes-evangelie die vertaling van 'n Aramese oorspronklike was, en in 1933 het Prof. C. C. Torrey in „The Four Gospels" beweer dat al vier evangelies vóór 60 ontstaan het, en vertalings is van oorspronklike aramese dokumente. 
Verdere ondersoek het aangetoon dat die stellinge van Dalman en Torrey onhoudbaar was, en korrigeer moes word. M. Black, wat ook ondersoek ingestel het na die Aramese agtergrond van die Evangelies het 'n noukeurige analiese gemaak van Aramese trekke in sinsbou, grammatika en woordeskat van die Evangelies. Hy het bevind dat die hipoteses van Evangelies wat direk uit Aramees vertaal is, afgewys moet word. Wat wel vasstaan is dat daar 'n Aramese Logia-bron ten grondslag lê aan die Sinoptiese tradisie, hetsy skriftelik, soos bv. die Q-dokument, of mondeling. Hierdie wyse van benadering het vrugbaar geblyk vir 'n betere verstaan van die Nuwe Testament.

'n Belangrike bydrae vir die verstaan van die Nuwe Testament is gelewer deur H. L. Strack en P. Billerbeck wat in 192228 hulle „Kommentar zum Neuen Testament, Ereäuterungen aus Talmud und Midrasch" die lig laat sien het. Jesus self en die skrywers van die Nuwe Testament was (behalwe Lukas) lede van die Joodse volk. Om hulle geskrifte te verstaan, is dit ook nodig om die lewe en denke en godsdienstige lewe van die Jodendom van daardie tyd te verstaan. Strack en Billerbeck het in hierdie Kommentaar 'n groot rykdom van toeligtende materiaal uit die Talmud en Midrasj byeengebring, om 'n objektiewe beeld te gee van die geloof, beskouinge en lewe van Jode in die eerste eeu, asook van die oudste Christendom. Die resultaat van hierdie lyn van ondersoek is die insig dat eksegetiese arbeid aan die Nuwe Testament, sonder om met die Ou Testamenties- Joods-Aramese agtergrond erns te maak, vandag ondenkbaar is.

Sedert die werk van Deissmann op die gebied van die ondersoek van die papyri, het 'n lewendige belangstelling ontstaan op die gebied van die grammatika. Sindsdien het 'n hele aantal grammatikas op die Grieks van die Nuwe Testament verskyn. Na J. H. Moulton se „Introduction to the New Testament Greek" in 1906 het in 1914 van A. T. Robertson verskyn sy "Grammar of the Greek New Testament — in the light of historical Research". Verder kan ons o.a. noem die grammatikas van Blass-Debrunner, L. Radermacher, 1911, 1952, de Zwaan, Nãgeli, Souter, Milligan en C. F. D. Moule se „An Idiom of the New Testament Greek", 1953, $1959^{2}$ )

As die keur van die oes aan woordeboeke vir die Griekse Nuwe Testament in die laaste halwe eeu kan gerus genoem word: W. Bauer - E. Preuschen se Griechisch-Deutsches Wörterbuch zu den Schriften des Neuen Testaments und der übrigen 
urchristlichen Literatuur, 1928', 1958'. 'n Vertaling van hierdie Woordeboek in Engels het reeds in Chicago, 1957, van die hand van W. F. Arndt en F. W. Gingrich verskyn. J. H. Moulton en G. Milligan se „The Vocabulary of the Greek Testament, illustrated from the Papryi and other non-literary Sources", 1914-1929 het hierdie verdienste dat die skrywers gebruik gemaak het van die winste wat die opgrawings van die ostraca en papyri in Egipte vir die Grieks van die Nuwe Testament opgelewer het. Maar van die allergrootste betekenis vir die taalkundige en teologiese verstaan van die Nuwe Testament is seker die grootse werk: "Theologisches Wörterbuch zum Neuen Testament" wat in 1933 deur G. Kittel begin is, en sedert sy dood op 11 Julie 1948 uitgegee word deur Gerhard Friedrich. Hierdie werk gee 'n begripshistoriese beskrywing en vra na die teologiese inhoud van alle Nieu-Testamentiese woorde wat enigsins besondere religieuse en teologiese betekenis het. Hierdie aksent op die teologiese weerspieël 'n wending wat ingetree het in die teologiese denke, asook in die karakter van die kommentare wat vroeër 'n oormaat van literêr-grammatikale analiese gegee het, maar nou ook vra na die teologiese inhoud, sodat soms gepraat word van 'n "teologiese eksegese". Hierdie onderneming kan sig verheug in die medewerking van 'n groot aantal uitnemende geleerdes. Die werk het nou gevorder tot die vierde Aflewering van Band 8, tot by die woord „hupotupósis”. Vir elke ernstige student van die Nuwe Testament kan seker ten opsigte van hierdie werk as goeie raad geld: Gaan heen, en verkoop alles wat jy het, en koop vir jou 'n Kittel! Dis verblydend dat daar gevorder word met die vertaling in Engels van hierdie uitnemende skat van teologie. 'Dit moet heilsaam inwerk in die engelssprekende wêreld waar die teologie van die Metodisme en van die Social Gospel sy vervlakkende invloed uitoefen.

\section{Die Teks van die Nuwe Testament}

, In die moeisame arbeid van vergelyking van die baie teksgetuies van die Nuwe Testament, met die doel om so na as moontlik aan die oorspronklike teks van die Nuwe Testament te kom, was Bengel die eerste om 'n ordening in die massa teksgetuies te skep, deur in die Manuskripte families te onderskei. Westcott en Hort het hiermee voortgegaan. Hulle het in die teksgetuies, - papyri, majuskel en minuskelhandskrifte en ou vertalings - vier groepe of families verteenwoordig gevind, nl. die Siriese (of Koine of Ryksteks, of Bisantynse teks), die Neutrale, Alexandrynse en Westerse teksfamilies. Omdat Westcott en 
Hort die Siriese of Koine of Ryksteks laat en onsuiwer geag het, en die sogenaamde Alexandrynse familie eigenlik as 'n satelliet van die Neutrạle Teks beskou het, lê die keuse meesal tussen die Neutrale en die Westerse tekste. Westcott en Hort sien in die Westerse teks die resultaat van 'n losbandige hantering van vroeë afskrywers, wat die neiging vertoon om die teks uit te brei met verduidelikinge en toevoeginge. Westcott en Hort kies dus vir die Neutrale Teks met die Vaticanus, B, as belangrikste verteenwoordiger. Die werk van die tekskritici het meegebrnig dat die Textus Receptus se heerskappy begin wankel het, en vervang is deur die Neutrale teks. Tog het die voorstanders van die Textus Receptus, soos Dean Burgon, die teorie van Wescott en Hort heftig bestry en dit opgeneem vír die Textus Receptus. Teen die end van die 19de eeu het die meeste ondersoekers die klassifikasie van Westcott en Hort aanvaar. Tog het daar vir die eerste dekades van die 20ste eeu, tot so laat as' 1933 (bv. A. C. Clark van Oxford) 'n heftige stryd ontbrand vir die teks van die Codex Besae en die Otrdlatynse vertaling as die belangrikste verteenwoordigers van die Westerse teks, en teen die Neutrale teks. In 1924 het B. $\mathrm{H}$. Streeter 'n nuwe teksfamilie geïdentifiseer, die sogenaamde Caesareateks wat verteenwoordig word deur die Koridethi-evangelies en die Minuskelfamilies 1 en 13 en W en P45. Volgens Streeter en Kenyon staan hierdie Caesarea-teks tussen B en D. Die Caesarea-teks is dus 'n nuwe toevoeging tot ons tekś-apparatus. Meer ondersoek is nodig om die karakter van hierdie familie sonder twyfel vas te stel. Dis verwant aan die Neutrale teks en tog verskillend. Die teorie van Westcott en Hort moes dus enigsins gewysig word. Geen tekstipe is volkome neutraal en ongeskonde nie. Hoewel die Neutrale teks met B as hoofverteenwoordiger die betroubaarste teks van die Nuwe Testament verteenwoordig, moet daar tog met die Westerse teks rekening gehou word. Kenyon ag dit wenslik om die teks wat verteenwoordig word in die Siriese vertalinge van die Nuwe Testament te onderskei as 'n afsonderlike teksfamilie wat die Siriese teks genoem kan word. Volgens Kenyon is hierdie teksvorm gevorm op die basis van die Neutrale teks, maar dit het sterk invloede van die Westerse teks ondergaan. Deur verskillende revisies wat hierdie teksvorm ondergaan het, het dit nie veel waarde vir die vasstelling van die oorspronklike teks in hierdie gebied nie, en moet versigtig gebruik word.

Die belangrikste aanwins van Nieu-Testamentiese handskrifte in hierdie eeu is die ontdekking van die Chester Beatty 
Papyri in 1931, wat bestaan uit 3 Codices, P45, P46, P47, wat respektiewelik belangrike gedeeltes van Evangelies en Handelinge, Paulusbriewe en die Openbaring van Johannes bevat. Die betekenis van hierdie ontdekking lê daarin dat dit die gaping tussen die oorspronklike teks en die oudste Manuskripte van ' $n$ belangrike deel van die Nuwe Testament aansienlik verminder het.

Ook die papyri en papyri-fragmente wat die afgelope dekades ondersoek is, bevestig die oortuiging van die deskundiges dat die teks van die Nuwe Testament oor die algmeen betroubaar oorgelewer is. 'n Belangrike vordering in hierdie eeu lê hierin dat die resultate van hierdie moeilike werk van bestudering en vergelyking deur deskundiges van die duisende teksgetuies vir die deursnee-teoloog toeganklik en bruikbaar gemaak is deur verskillende tekskritiese uitgawes van die Nuwe Testament, uitgawes wat in die vorm van tekskritiese aparaat onder aan elke bladsy van die teks die belangrikste lesinge weergee sodat die leser 'n oordeel kan vorm. Die bruikbaarste uitgawe is seker die Novum Testamentum Graece wat in 1898 deur Eberhard Nestle uitgegee is, en daarna deur Erwin Nestle opnuut bewerk is, in 1927 sy 13de druk beleef het, en in 1960 met die medewerking van Kurt Aland die 24ste druk bereik het. Hierdie teksuitgawe wou die deursnee resultaat aanbied van die teksondersoek van die 19de eeu, met die bedoeling dat dit die toe-nog-wydverbreide Textus Receptus moet vervang. Eberhard Nestle het die groot wetenskaplike uitgawes van die 19de eeu, m.n. van C. Tischendorf, Westcott-Hort en Weymouth (sedert 1901 vervang deur $\mathrm{B}$. Weiss) ten grondslag aan sy uitgawe gelê. So is 'n Nieu-Testamentiese teks met objektiewe karakter verkry. Dit het 'n algemene ingang gevind en is wyd verbrei, ook deur die feit dat die Britse en Buitelandse Bybelgenootskap in 1904 besluit het om hierdie teks te gebruik in die plek van die Textus Receptus, en dit ten grondslag te lê aan sy sendingvertalinge. Hierdie teks het ingang gevind en word gebruik oor die hele wêreld.

In die teken van die tyd staan 'n teksuitgawe van die Nuwe Testament wat in 1966 verskyn het onder die titel : „The Greek New Testament, Edited by Kurt Aland, Matthew Black, Bruce M. Metzger and Allen Wikgren. Hierdie uitgawe is eigenlik 'n onderneming van die American Bible Socitey, The British and Foreign Bible Society, die Nederlandse Bybelgenootskap. The National Bible Society of Scotland en die Württemberg'sche 
Bibelanstalt, - met die bedoeling dat daar 'n eenstemmige teks beskikbaar sal wees vir alle vertalings van die Nuwe Testament in die toekoms.

\section{Vertalinge van die Nuwe Testament}

Die afgelope half-eeu is gekenmerk deur 'n ruim getal vertalinge van die Bybel, en afsonderlik van die Nuwe Testament, - vertalinge wat onderneem is deur Bybelgenootskappe, kerke en geleerdes. Baie vertalinge het tot stand gekom, om te dien in die werk van die sending; andere is gemaak met die oog op gebruik in gevestigde Christelike kerke, wat die taal van die ou vertalinge nie meer begryp nie. Daarom was dit die strewe om die Nuwe Testament te laat spreek in die taal van die 20 ste eeu, sodat die mense van vandag dit kan verstaan. Sedert die begin van die 20ste eeu het vir die engelssprekende wêreld verskillende sulke vertalinge die lig gesien. Kort na „The Twentieth Century New Testament" (voltooi 1901, hersiene uitgawe 1904 ) het in 1902 verskyn die vertaling van W.R. Weymouth, en hierop het in 1913 gevolg die uitstekende vertaling van Prof. J. Moffatt, en in 1923 in Amerika die vertaling van Prof. Goodspeed en in 1946 die Revised Standard Version, weer uit Amerika. Die vertalinge van Moffatt en Goodspeed, in eenvoudige en direkte Engels gestel is van die beste wat deur individuele geleerdes in die Engelssprekende wêreld gelewer is.

In Nederland het in 1912 die Leidse Vertaling verskyn, wat die vrysinnige karakter dra van die Leidse skool uit die tweede helfte van die vorige eeu. In 1925 verskyn die mooi vertaling van Prof. A. M. Brouwer, wat 'n kolometriese vertaling gee van poëtiese gedeeltes van die Nuwe Testament, en in 1939 die nuwe vertaling van die Nederlandse Bybelgenootskap. Vertalinge van individuele geleerdes van gedeeltes van die Nuwe Testament het ook van tyd tot tyd in kommentare verskyn.

In Europa, veral in Duitsland is die oes van Bybelvertaling groot, meestal in die vorm van vertalinge van individuele geleerdes in kommentare-reekse en kommentare op enkele boeke van die Nuwe Testament.

In 1933 kon in ons land die Bybel in Afrikaanse vertaling in gebruik geneem word. Vyf-en-twintig jaar later, in 1958 is die Bybel met verklarende Aantekeninge uitgegee deur die Verenigde Protestantse Uitgewers (Edms.) Bpk. Hierdie uitgawe is gereed gemaak onder redaksie van 'n aantal teoloë uit die drie Afrikaanse kerke. En al is die Vertaling in Afrikaans oor die algemeen 'n goeie vertaling, tog moet, wat die Nuwe Testament betref, die werk van die Bybelvertaling voort- 
gaan in die vorm van hersiening. Dit word behartig deur die Kommissie vir die Hersiening van die Afrikaanse Bybel. Daar is nog heelwat gevalle waar van die tekskritiese resultate nie voldoende gebruik gemaak is nie, en nog vasgehou word aan lesinge van die Textus Receptus. 'n Goeie vertaling is reeds in sekere opsig 'n verklaring van die Skrif.

\section{Eksegese}

Deur sware, toegewyde en intensiewe arbeid is die NieuTestamentici van vandag uitnemend voorsien van hulpmiddels vir eksegese van die Nuwe Testament. Die gereed maak van die belangrikste hulpmiddels vir die verstaan van die Nuwe Testament is een van die kenmerke van die Nieu-Testamentiese ondersoek van die afgelope halwe eeu. In al hierdie moeisame abeid is die uiteindelike doel die verstaan van die Nuwe Testament, die verstaan van die boodskap wat die Woord van God het vir ons mense van die 20ste eeu. Daarom is dit verblydend dat die hermeneutiek, die teorie van die vertolking, met ander woorde die wetenskap van die verstaan tans in die sentrum van die belangstelling staan. Dit blyk reeds uit 'n reeks van hermeneutiese handboeke en geskrifte wat sedert 1926 verskyn het, bv. van Von Dobschütz 1927, J. Wach 1926, E. Fascher 1930, F. Torm 1930, R. Bultmann 1950, E. Lerle 1951, E. Fuchs 1954, E. Ebeling 1959 (in R.G.G.) A. N. Wilder 1962, e.a.. Ook in die Nederduitsche Hervormde Kerk het daar 'n belangstelling in die Hermeneutiek aan die dag begin tree, 'n belangstelling wat verblydend is.

Die verandering in die eksegetiese benadering, wat in die afgelope halwe eeu ingetree het, kan van die aard van die kommentare afgelees word. Nog 'n paar dekades terug het die nadruk gelê op grammatikale analise en bronnesplitsinge en die aandra van godsdiens-historiese parallelle om die Nuwe Testament te verklaar. Tans lê die nadruk op die teologiese, op die sin en betekenis van die Skrif, sonder om noodsaaklike grammatikaal-historiese eksegese prys te gee. Naas die streng- wetenskaplike kommentare, wat vir teoloë bedoel is, kam al meer kommentare na vore wat met die oog op gewone lidmate van die kerk in populêre vorm aangebied word, sonder om die wetenskaplike gehalte in te boet. As voorbeeld van wetenskaplike kommentare kan ons bv. noem die H. A. W. Meyer-reeks wat reeds meer as 'n eeu gelede begin is, maar telkens weer in nuwe bewerking verskyn. Kommentare wat ook deur die niegeskoolde leser verstaan kan word is bv. die Serie Teks en 
Uitleg, die Korte Verklaring der Heilige Schrift met nieuwe Vertaling, die Serie Prediking van het Nieuwe Testament, die Black's :New Commentaries, ens.t

\section{Die Sinoptiese Ondersoek}

Nadat B. H. Streeter se Vierbronne-hipotese (1924) algemeen aanvaar is as die beste oplossing van die sg. Sinoptiese probleem, het daar 'n nuwe benadering tot die probleem van die oorspronge van die Evangelies opgekom. Dis die sg. „Formgeschichtliche;,', benadering wat 'n ondersoek instel na die mondelinge tradisie wat in ons Evangelies literêre vorm aangeneem het, met die oorrtuiging dat die raamwerk, die literêre vorme waarin die Evangeliestof gekomponeer is, nie tot die oorspronklike tradisiestof behoort nie, maar van die Evangeliste self afkomstig is. Elke Evangelis gaan met die ordening en vormgewing van sy stof volgens eie plan te werk. Eers ná die eerste wêreldoorlog het die voorstanders van die „Formgeschichtlichte” metode 'n planmatige ondersoek ingestel na die evangelietradisie. Volgens hulle shet die vormgewing van die stof in die Evangelies plaasgevind volgens vaste wette wat verskil namate die litẹrere „Gattungen" wat gebruik word, verskil, bv. sprokies, sages, liedere, spreuke, ens. So het bv. K. L. Schmidt aangetoon dat in die Evangelie volgens Markus die raamwerk van die vertelling die werk van die skrywer is, en dat in hierdie raamwerk die los gedeeltes van die oorleweringstof tot 'n planmatige eenheid saamgevoeg is. Ook M. Dibelius en Bultman het hięrdie metode op die evangeliese tradisie-stof toegepas. Volgens Dibelius en Bultman het die Evangeliestof reeds in die jare 30-60 diepgaande veranderinge ondergaan, en is deur die vormgewing in die Evangelies veelvuldige veranderinge aangebring en is vreemde stowwe opgeneem wat oorspronklik met die bedoeling van Jesus niks te doen gehad het nie. Hiervolgens bly daar van die geskiedenis van Jesus omtrent niks sekers oor nie. So 'n beskouing kan ons nie aanvaar nie, in die aangesig van die duidelike en ondubbelsinnige getuienisse van die sterk historiese belangstelling van die oudchristelike verkondiging, (vgl. bv. Hand. 2:22v.; 10:37; I Kor. 11:23v.; I Kor. 15:3v., ens.). Die Apostels sou nie so 'n vervalsing en omvorming van die oorspronklike Jesus beeld toegelaat het nie. Al is die uitgangs punt van die „Formgeschichtliche Metode" waardevol, tog is die toepassing en resultate meermale bedenklik. Intussen het die „Formgeschichte” oorgegaan in die „Traditionsgeschichtliche” metode, wat in die Sinoptiese evangelies verskillende tradisielae vind, - en het die Redaktionsgeschichte begin werk met die 
hipotese van verskillende redaksies of bewerkinge van die stof in die Sinoptiese Evangelies. Ewewel die belangstelling in die ondersoek aan hierdie front duur voort. En die gebruik van 'n besonne hermeneutiek is hier noodsaaklik. Ons laat dit by hierdie enkele opmerkinge om vir 'n oomblik te kyk na die Paulusondersoek.

\section{Die Paulus-ondersoek}

Die Paulus ondersoek verteenwoordig 'n veelbewoë hoofstuk in die Nieu-Testamentiese teologie. Reeds sedert ongeveer die helfte van die vorige eeu was daar ' $n$ intense worsteling oor die vraag hoe Paulus teologies en histories geplaas en verstaan moet word. Werke soos Paul Feine se "Der Apostel Paulus. Das Ringen um das geschichtliche Verstāndis des Paulus", 1927 en A. Schweitzer se "Geschichte der Paulinischen Forschung von der Reformation bis auf die Gegenwart" 1911, 1933 " gee vir ons ' $n$ indruk van die omvang van hierdie ondersoek. Daar is hier vier beskouinge te onderskei: (a) Die intellektualistiesleerstellige rigting wat in Paulus 'n dogmatiese sisteembouer gesien het, en wat na sy leerbegrippe gevra het. Hier is die lewende mens en apostel Paulus begrawe onder 'n Paulinisme. Hierdie beskouing het saam met die rasionalisme en die intellektualisme van die vorige eeu verbygegaan. (b) Hierop het gevolg die godsdienshistoriese rigting wat die Christendom geplaas het in die raamwerk van die antieke godsdienste, en wat beînvloeding aangeneem het, soos bv. van die hellenistiese misteriegodsdienste en die orientalistiese sinkretisme. Die hipotese dat Paulus in Tarsus sterk hellenistiese beinvloedinge ondergaan het eerdat hy na Jerusalem gekom het, word weerlê deur uitsprake soos Hand. 22:3 en 26:4, waarvolgens Paulus sê dat hy in Tarsus gebore is, maar in Jerusalem grootgemaak is (anatethrammenos) en opgevoed (pepaideumenos) aan die voete van Gamaliël, - dat hy sy lewe onder sy nasie van die begin af in Jerusalem deurgebring het. Paulus moes dus as kind na Jerusalem gekom het. Volgens geleerdes soos Reitzenstein, W. Bousset en $\mathrm{K}$. Lake het Paulus se sakramentsopvattinge invloed van die misteriegodsdienste ondergaan. Maar so kom die spesifiek-Christelike by Paulus nie tot sy reg nie, en die verteenwoordigers van die godsdienshistoriese skool is dikwels verblind deur uitwendige analogië en het nie geslaag om deur te dring tot die wesenlike van die Christelike godsdiens nie. (c) Ook die konsekwente eskatologie van Kabisch, Teichmann en Schweitzer was nie in staat om die kenmerkende van Paulus se teologie en godsdiens te verklaar nie. (d) Toe het aan die 
begin van hierdie eeu 'n wending ingetree, weg van die leerstellinge en na die religieus beskouinge toe. Hier is dit veral manne soos Ramsay en Deissmann wat die lewende mens en apostel Paulus bevry het van die dooie gewig van intelektualistiese Paulinisme, waaronder die vorige eeu hom begrawe het. Sedert ongeveer die begin van ons eeu het die besef posgevat dat Paulus verstaan moet word soos hy uit sy eie woorde verstaan wil word: nie as mistikus, ekstatikus of dogmatikus nie; nie uit 'n alternatief van Jesus of Paulus nie, ook nie as die stigter van die Christendom of as vervalser van die oorspronklike Evangelie nie. $\mathrm{Na}$ al die geleerde verdwasing het die besef deurgebreek dat Paulus gesien moet word as Apostel van Jesus Christus die Gekruisigde, as slaaf van Jesus Christus, aan wie hy behoort na gees en siel en liggaam. Sy hele godsdiens kan saamgevat word in die woorde: in Christus wees, in gemeenskap met Christus lewe. Paulus het net één liefde, één hartstog geken: Christus was vir hom alles. Sy godsdiens en denke moet teen die agtergrond van die Ou Testament verstaan word. Ten opsigte van Israel was Paulus 'n Hebreër uit die Hebreërs, (Fp. 3:5) . . . en nie 'n renegaat nie. As ons hom 'n religieuse genie wil noem .... dis nie dít wat hom die groot apostel en eerste teoloog van die Christelike kerk gemaak het nie, maar die genade van Christus wat hom geroep het en gestuur het om Christus te verkondig. Dit was die Christusprediking van Paulus wat vir die Christendom in die eerste eeu die groot oorwinningsloop deur die antieke wêreld besorg het. Dit is die boodskap van Paulus vir die kerk van die 20ste eeu: die krag van die oorwinning lê in die Evangelie van Jesus Christus.

Ten opsigte van verskillende Inleidingsvrae in verband met die Corpus Paulinum is die laaste woorde nog nie gespreek nie; selfs nou nog is daar vrae wat oopgelaat moet word omdat besliste antwoorde nog nie gegee kan word nie. Enkele van hierdie vrae is: Was Paulus die outeur van die Pastorale briewe? of het 'n Paulus-leerling daarin Paulus-fragmente verwerk? Aan watter gemeentes is die brief van Galate gerig: Noord- of Suid-Galasië ? Waar het Paulus die gevangeskapbriewe geskryf : Rome of Efese, of miskien Caesarea? Was hoofstuk 16 van die brief aan die Romeine vir Rome bestem? Of miskien vir Efese? Het ons in 2 Korintiërs eén brief of twee: $1-9$ en 10-13?

Ons moet dit laat by hierdie paar opmerkinge oor die verstaan van die apostel Paulus. 


\section{Enkele tendense in die Nieu-Testamentiese Teologie.}

Die Nieu-Testamentiese teologie het in die afgelope halwe eeu 'n verdieping beleef. Die roes van 'n evolusionistiese optimisme van die 19de eeu, die geloof indie vooruitgang van die mensheid na die volmaaktheid, die vorwagting van 'n koninkryk van menslike ideale en doeleindes $6 \mathrm{p}$ aarde het in duie gestort. Die welversekerde optimisme dat daar goed gevorder word met die opvoeding van die mensheid., deur die wyse beleid van die goddelike Voorsienigheid" is verpletter deur die demoniese uitbarsting van haat en geweld in die eerste wêreldoorlog. 'n Somber pessimisme het sig van baie harte meester gemaak. Onder hierdie omstandighede het die skool van Karl Barth opgetree, en 'n felle aanval gedoen op die liberale Godsvoorstelling van die 19de eeu. Die God van die Bybel is die Geheel-Andere, die Onbegryplike, die Heilige, die Ewige. Hy kan nie vasgevang word in 'n aardse koninkryk van menslike doeleindes nie. Hy is die God wat hom in Iesus Christus geopenbaar het, en nie 'n God wat deur mense uitgevind word nie. Die eskatologie het weer sy regmatige plek gekry, en die geloof gerig op die dimensie van die ewigheid. Die „LebenJesu" beskrywinge en die liberale Jesusbeeld het plek gemaak vir ' $n$ intense belangstelling in die werklike Christologie van die Skrif. Die individualisme van die losloper vromes van die 19de eeu moes wyk voor die Nieu-Testamentiese leer van die kerk, as die plek waar Christus self sy gemeente saambring tot die ware gemeenskap in Hom, 'n gemeenskap wat gesien moet word in eskatologiese perspektief, as die gemeente van die eindtyd, - 'n gemeenskap wat sy ware gemeenskap in Christus het.

Verder word die Nieu-Testamentiese teologie van ons tyd hierdeur gekenmerk dat daar tans meer nadruk gelê word op die wesenlike eenheid in die kerygma van die Nuwe Testament. Die voorafgaande tyd het die nadruk laat val op die verskeidenheid in die leerinhoud van die Nuwe Testament, sodat in leerboeke agtereenvolgens verskillende teologieë beskryf is, (bv. Sinopties, Johanneïes, Paulinies, ens.). Nou word gevra na die eenheid wat ten grondslag aan die verskeidenheid lê. Daarom dat leerboeke soos dié van Holtzmann en Feine plek moes maak vir werke wat die wesenlike, die gemeenskaplike, die eenheid van die Nieu-Testamenties verkondiging op die voorgrond stel.

Maar nieteenstaande die verdieping in die verstaan van die Nuwe Testament is daar tog tendense aan die werk waarteen gewaak moet word. Ons noem hier net twee dinge: (a) In 
die sterk ekumeniese strewe van ons tyd, in die drang na eenheid op allerlei gebiede, skuil die gevaarlike neiging om die eenheid van die kerk te wil realiseer 'ás 'n mensgemaakte eenheidsorganisasie, sonder en ten koste van die eenheid van die geloof, sonder die eenheid in die Gees, die eenheid wat in Jesus Christus geskenk is. Hierdie uiterlike organisatoriese eenheidsdrang is op pad na Rome. (b) Die tweede tendens wat ons noem staan in verband met die misverstaan van die koninkryk van God as 'n "diesseitige" Utopia wat deur die mense geskep word, 'n gemeenskap vry van armoede, sorge en nood, die koninkryk van die "Social Gospel". Maar so word die eskatologiese perspektief van die Nuwe Testament en daarmee die hoop en troos van die Christelike geloof prysgegee. So kom die Koninkryk van God nie as die koninkryk wat nie van hierdie wêreld is nie, maar as 'n koninkryk wat die vrugte op die a'ksie van die mense is, om ideale omstandighede te skep om in hierdie wêreld sorgury en menswaardig te lewe. In Jesus Christus het die koningsheerskappy van God in hierdie wêreld gekom. En in die tussentyd tot by die wederkoms van Christus is Sy koningsheerskappy nog verborge en regeer Hy deur Sy Woord en Gees. Maar ons verwag die voleinding van hierdie koninkryk wanneer die godsheerskappy in volle mag en heerlikheid sal kom. Dis die onwankelbare ewige koninkryk wat ons verwag, 'n koninkryk nie van hierdie wêreld nie. 